\title{
Adult T-cell Leukemia (ATL) Cells which Express Neural Cell Adhesion Molecule (NCAM) and Infiltrate into the Central Nervous System
}

\author{
Teruto Hashiguchi ${ }^{* * *}$, Mitsutoshi TARA*, Kiyoshige NiInA*, Itsuro HiguChI***, Kimiyoshi Arimura***, \\ Mitsuhiro OSAME*** and Ikuro MARUYAMA**
}

\begin{abstract}
We encountered a patient with adult T-cell leukemia/lymphoma (ATL) which expressed neural cell adhesion molecule (NCAM). The tumor cells markedly infiltrated the central nervous system (CNS) during the course of the ATL. The patient died 20 months after disease onset, which was considered to be early in the course. During the invasion of the CNS, the surface phenotype of the peripheral blood ATL cells by flow cytometric analysis was $\mathrm{CD2}+, \mathrm{CD3}+, \mathrm{CD4}+$, CD7-, CD8-, CD16-, NCAM (CD56)+, HLA-DR-. We speculate that the infiltration of ATL cells into the CNS was closely related to the expression of the NCAM in this patient.

(Internal Medicine 41: 34-38, 2002)
\end{abstract}

Key words: CD56, CD16, natural killer (NK) cells, peripheral T-cell lymphoma (PTCL), invasion

\section{Introduction}

Adult T-cell leukemia/lymphoma (ATL) is a peripheral Tcell leukemia/lymphoma caused by human T-cell lymphotropic virus type I (HTLV-I) (1). More frequently than other hematopoietic tumors, ATL infiltrates organs such as the central nervous system (CNS), skin, lung, and gastrointestinal tract (2). When invading the skin, ATL cells reportedly express a variant type of Sialyl Lewis X antigen (3), thus demonstrating the importance of the relationship between adhesion molecules and organ infiltration by ATL cells. NCAM is a member of the immunoglobulin superfamily and is a glycoprotein expressed on the surfaces of various cells, including brain, nerve, muscle and natural killer (NK) cells (4-6). NCAM has also been expressed on the surfaces of various tumor cells, including small cell carcinoma of the lung, neuroectodermal tumors such as neuroblastoma, malignant melanoma, glioma, peripheral nerve and muscle tumors, multiple myeloma, and Wilms tumor (714).

NCAM-positive peripheral T-cell lymphoma (PTCL) was first described in 1992 by Kern et al (15) as a rare variant with a characteristic phenotype from NCAM-negative PTCL. NCAM-positive PTCL patients reportedly exhibit a striking predilection for unusual extranodal involvement including the CNS, muscle, gastrointestinal tract, and nasopharynx.

We report an NCAM-positive ATL patient in whom ATL cells markedly infiltrated the CNS. In this patient, ATL cell infiltration in the CNS may have been closely related to the expression of NCAM. NCAM is an adhesion molecule for neurons that may be important in elucidating the organ-infiltration mechanism of ATL cells in patients with a poor prognosis.

\section{Case Report}

In September 1995, leukocytosis was noted during a health examination of a 49-year-old Japanese man born in Kagoshima Prefecture, which was considered an HTLV-I endemic area. During our initial examination, including whole body imaging and magnetic resonance imaging (MRI) of the head, we found no indication of organ infiltration by tumor cells. Serum antibody against HTLV-I was positive. The peripheral white blood cell count was 30,700/ $\mu 1$, flower cells were $80.5 \%$ (CD4/8 ratio, 10.24), and lactate dehydrogenase (LDH) was 1,025 W.U. (normal range: 50-400). The serum concentration of soluble interleukin 2 receptor was $27,100 \mathrm{U} / \mathrm{ml}$. The disease was diagnosed as acute ATL based on the criteria of Shimoyama (16). Remission induction therapy was done as follows: Week 1: 40 $\mathrm{mg} / \mathrm{m}^{2}$ (40 $\mathrm{mg}$ per $1 \mathrm{~m}^{2}$ body surface area) of prednisolone, 1 $\mathrm{mg} / \mathrm{m}^{2}$ of vincristine sulfate, $350 \mathrm{mg} / \mathrm{m}^{2}$ of cyclophosphamide, $40 \mathrm{mg} / \mathrm{m}^{2}$ of doxorubicin hydrochloride; Week $2: 40 \mathrm{mg} / \mathrm{m}^{2}$ of prednisolone, $30 \mathrm{mg} / \mathrm{m}^{2}$ of doxorubicin hydrochloride, $60 \mathrm{mg} /$

From *the Department of Internal Medicine, Kagoshima City Hospital, Kagoshima, **the Department of Clinical Laboratory Medicine, and $* * *$ the Third Department of Internal Medicine, Kagoshima University, Kagoshima

Received for publication January 25, 2001; Accepted for publication September 29, 2001

Reprint requests should be addressed to Dr. Teruto Hashiguchi, the Department of Clinical Laboratory Medicine, Kagoshima University, 8-35-1 Sakuragaoka, Kagoshima 890-8520 
$\mathrm{m}^{2}$ of ranimustine; Week $3: 40 \mathrm{mg} / \mathrm{m}^{2}$ of prednisolone, $2.4 \mathrm{mg}$ / $\mathrm{m}^{2}$ of vindesine sulfate, $100 \mathrm{mg} / \mathrm{m}^{2}$ of etoposide, and $250 \mathrm{mg} /$ $\mathrm{m}^{2}$ of carboplatin. Soon after this regimen (prednisolone, oral; other drugs, intravenous), cytarabine ocfosfate ( $25 \mathrm{mg} /$ day) was orally administered for approximately six months, and partial remission (atypical lymphocytes: 5-8\%) was maintained. In August 1996, the patient started to manifest psychiatric symptoms. Abnormal shadows indicating tumor cell infiltration in the CNS were observed on cephalic MRI (Fig. 1), and ATL cells were found in the cerebrospinal fluid (cell count 14/3, flower cells $26.0 \%$ ). The psychiatric symptoms and abnormal shadows on cephalic MRI disappeared after an intravenous injection of $75 \mathrm{mg}$ of ranimustine (every week, three times in total) and an intrathecal injection of $10 \mathrm{mg}$ of prednisolone sodium succinate (every week, twice in total). In December 1996, the symptoms recurred, showing a peripheral white blood cell count of $14,400 / \mu 1$, atypical lymphocytes of $47.5 \%$, and LDH of 1,495 W.U. The patient was treated with the same combined chemotherapy as described above plus additional intrathecal chemotherapy. However, systemic surface and para-aortic lymphadenopathy examined by abdominal computed tomography was observed and the patient manifested central nervous system involvement such as an impaired level of consciousness, in addition to abnormal brain shadows on repeated MRI. The patient died in March 1997. Permission for postmortem

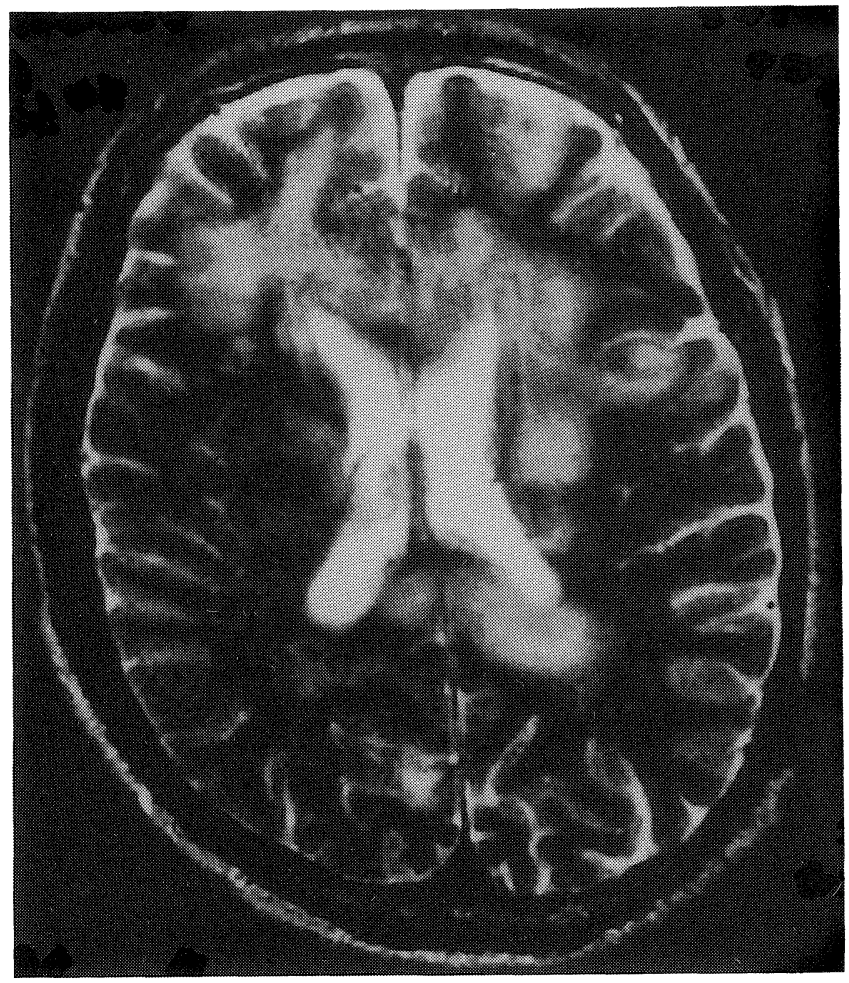

Figure 1. T2- weighted MRI. Increased signal intensities in both gray and white substances indicate diffuse infiltration of ATL cells into the central nervous system. examination was not obtained.

\section{Materials and Methods}

\section{Blot analysis of HTLV-I DNA and T-cell receptor gene}

Peripheral blood mononuclear cells (PBMC) from the patient at the time of diagnosis were isolated with Ficoll-Paque (Pharmacia, Uppsala, Sweden) using standard methods. Total cellular DNA was extracted from PBMC. The monoclonal integration of HTLV-I proviral DNA and T-cell receptor (TCR) $C \beta$ gene rearrangement was examined by EcoRI and BamHI digestion of DNA ( $5 \mu \mathrm{g})$, respectively. The DNA was transferred to nylon filters and hybridized with ${ }^{32} \mathrm{P}$-labeled HTLV-I DNA to examine the clonal proliferation of HTLV-I infected lymphocytes. T-cell receptor (TCR) genes were analyzed using a human T-cell receptor $\beta$ (TRB) locus $C \beta$ probe.

\section{Flow cytometric analysis}

Surface immunophenotyping of the leukemia cells was performed with flow cytometry using the following panel of lymphoid-associated monoclonal antibodies: T11 (CD2), T4 (CD4), T1 (CD5), 3A-1 (CD7), T8 (CD8), NKH-1 (CD56) (Coulter, Hialeah, FL, USA), Leu4 (CD3), Leu11a (CD16), anti IL-2R (CD25), and HLA-DR (Becton-Dickinson, Sunnyvale, CA, USA). Flow cytometric analysis was performed using a laser flow cytometer (JASCO, Tokyo).

\section{Detection of RNA transcripts}

mRNA was isolated from PBMC and reverse-transcribed using an mRNA purification kit and a first-strand cDNA synthesis kit (Amersham Pharmacia Biotech, Buckingham, UK), respectively. These were then subjected to 40 cycles of polymerase chain reaction (PCR) alternating at 1-minute incubations of $94^{\circ} \mathrm{C}, 65^{\circ} \mathrm{C}$ and $74^{\circ} \mathrm{C}$. The primers used were located at NCAM exons 11 and 14, and consisted of the sequences 5'-GAGGCCACAGGTGGGGTGCC-3' and 5'GCTGTGGGCTGGGCCGAGG-3'. The 525-bp product was predicted based on the known NCAM gene sequence (17). Reactions were performed in volumes of $50 \mu \mathrm{l}$, and $20 \mu \mathrm{l}$ was loaded onto a $1 \%$ agarose gel and visualized using ethidium bromide.

\section{Results}

Southern blot analysis revealed monoclonal integration of HTLV-I proviral DNA and a monoclonal rearrangement band of the TRB locus in peripheral blood lymphocytes (PBL) (Fig. 2).

At the time of CNS infiltration of ATL cells, surface markers of the leukemic cells in PBL analyzed using monoclonal antibodies were CD2, 93.6\%; CD3, 93.6\%; CD4, 94.9\%; CD5, 44.0\%; CD7, 0.8\%; CD8, 0.7\%; CD16, 2.2\%; CD25, 51.0\%; NCAM (CD56), 82.3\%; HLA-DR, 11.8\%; CD4+/8-, 94.7\%; CD4+/56+, 80.0\%; and CD56+/16-, 86.4\% (Fig. 3). Prior to CNS infiltration by ATL cells, the surface markers were CD2, 93.5\%; CD3, 90.2\%; CD4, 88.2\%; CD5, 82.2\%; CD7, $13.4 \%$; 


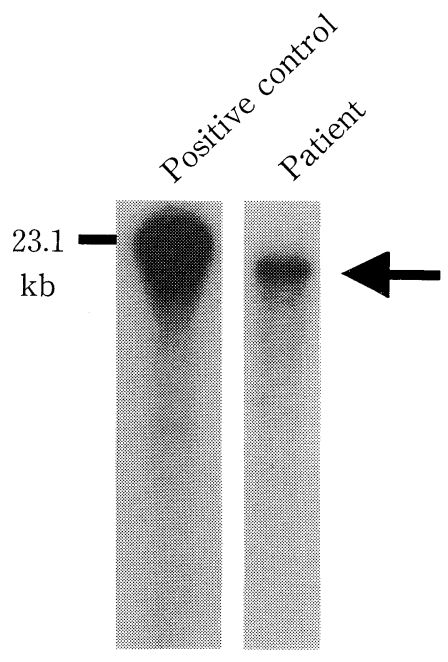

HTLV-I

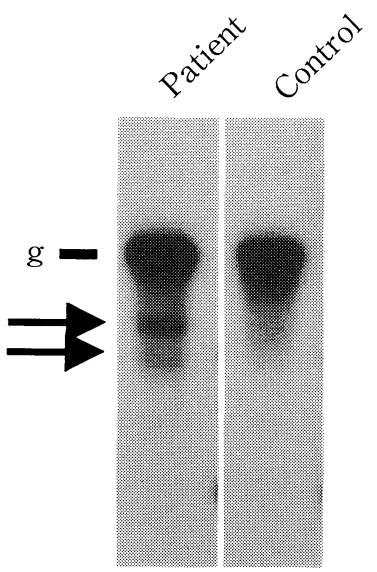

$\mathrm{T}$ cell receptor
CD8, 7.9\%; CD16, 2.6\%; CD25, 77.3\%; NCAM (CD56), $14.5 \%$; and HLA-DR, $36.9 \%$.

Agarose gel electrophoresis of the reverse transcriptase-PCR products demonstrated a band of approximately $525 \mathrm{bp}$, as predicted (Fig. 4).

\section{Discussion}

We report a patient with ATL which expressed NCAM, who showed intracerebral and leptomeningeal infiltration. The phenotypic and genotypic characteristics of this case which demonstrated both monoclonal integration of the HTLV-I proviral DNA and T-cell receptor $\mathrm{C} \beta$ gene rearrangement are those of

Figure 2. Southern blot analysis. The monoclonal integration of HTLV-I proviral DNA $(\leftarrow)$ and two rearrangement bands of the T-cell receptor (TCR) C $\beta$ gene $(\rightarrow)$ are observed. g: germ line band.
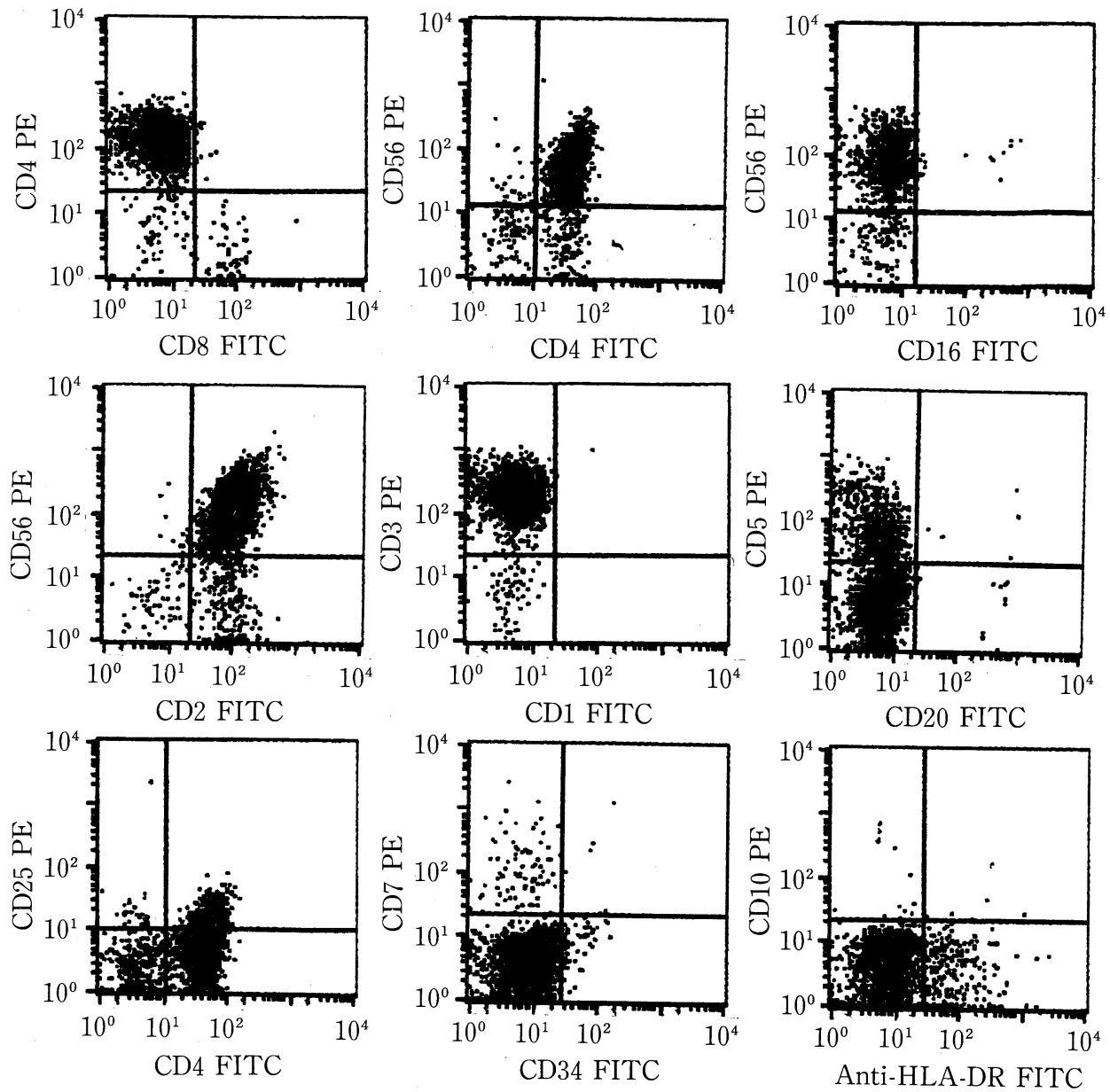

Figure 3. Flow cytometry analysis of ATL cells. Two-color analysis by flow cytometry clearly shows that the phenotype of ATL cells at the time of involvement of the central nervous system was CD4+/8-/56+/16-. 


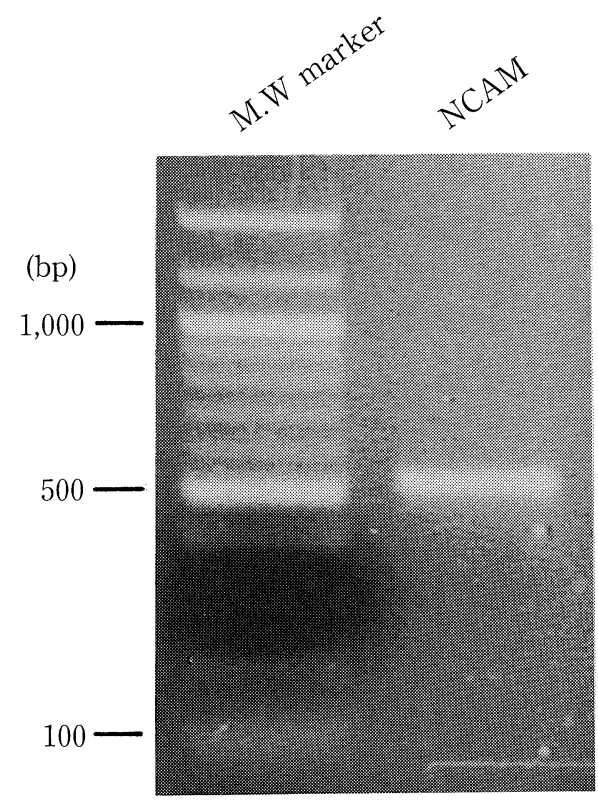

Figure 4. Agarose gel electrophoresis of PCR product. Fragment of approximately $525 \mathrm{bp}$ is, as predicted, present in the patient's sample.

ATL. The results of the reverse transcriptase-PCR assay, which found RNA transcripts consistent with NCAM in the patient's sample, support the likelihood that the flow cytometric analysis of the ATL cells by NKH-1 was related to NCAM and was not a cross-reactivity or NKH-1 false positivity. CD16 expression, which is the most constant marker of NK cells (18), was negative, and the histological features of the ATL cells in peripheral blood were no different from those of typical CD4+/ 8-156- ATL (19). Although ATL cells were previously reported to occasionally express NCAM (20-23), there has been only one case report of a detailed clinical course in which the patient showed unusual involvement of the gastrointestinal tract during the course of the disease (22). It has been reported that at least roughly $10 \%$ of all ATL patients manifest CNS involvement (24). The frequency of NCAM expression by ATL cells in patients with CNS involvement should be analyzed in the future.

NCAM-positive PTCL, proposed by Kern et al (15), was reported to show a striking predilection for unusual extranodal involvement including the CNS, muscle, gastrointestinal tract, and nasopharynx compared with NCAM-negative PTCL. Its characteristic phenotype is CD2+, CD56+, CD3-, CD5-. The phenotype in typical ATL is CD2+, CD56-, CD3+, CD5+. Patients with NCAM-positive ATL, including this patient, show a phenotype of $\mathrm{CD} 2+, \mathrm{CD} 56+, \mathrm{CD} 3+, \mathrm{CD} 5+$. This is a characteristic phenotype differing from those of NCAM-negative PTCL and typical ATL, suggesting that NCAM-positive ATL comprises a subgroup. In contrast to the marked increase of NCAM (CD56) expression, CD5, CD25 and HLA-DR were relatively decreased at the time of CNS invasion, suggesting that a clonal change of ATL cells must occur. Unfortunately, we did not use Southern blot analysis to examine the change of clonality of ATL cells at the time of CNS invasion.

Generally, infiltration of the CNS is rare in PTCL, and most lymphomas involving the CNS are of B-cell lineage (25). However, NCAM-positive PTCL has been reported to frequently involve the CNS. The CNS involvement in this patient was probably related to the homophilic binding characteristics of NCAM-expressing ATL cells and the CNS. Furthermore, it has been reported that the median survival time of patients with NCAM-positive PTCL is less than half that of patients with NCAM-negative PTCL (15). More analyses of clinical NCAMpositive ATL cases will provide clues to elucidate the significance of NCAM expression in ATL and the organ infiltration mechanism of ATL cells.

Acknowledgments: This work was supported by grants from the Ministry of Health and Welfare of Japan. We thank Dr. RL Rosales for his critical reading of the manuscript.

\section{References}

1) Uchiyama T, Yodoi J, Sagawa K, Takatsuki K, Uchino H. Adult T-cell leukemia: Clinical and hematologic features of 16 cases. Blood 50: 481492, 1977.

2) Uchiyama T. Adult T-cell leukemia. Blood Rev 2: 232-238, 1988.

3) Furukawa Y, Tara M, Ohmori K, Kannagi R. Variant type of sialyl Lewis $\mathrm{X}$ antigen expressed on adult $\mathrm{T}$ cell leukemia cells is associated with skin involvement. Cancer Res 54: 6533-6538, 1994.

4) McClain DA, Edelman GM. A neural cell adhesion molecule from human brain. Proc Natl Acad Sci USA 79: 6380-6384, 1982.

5) Cunningham BA, Hemperly JJ, Murray BA, Prediger EA, Brackenbury R, Edelman GM. Neural cell adhesion molecule: structure, immunoglobulin-like domains, cell surface modulation, and alternative RNA splicing. Science 236: 799-806, 1987.

6) Thomas PS, Pietrangeli CE, Hayashi S, et al. Demonstration of neural cell adhesion molecules on stromal cells that support lymphopoiesis. Leukemia 2: 171-175, 1988.

7) Kibbelaar RE, Moolenaar CE, Michalides RJ, Bitter-Suermann D, Addis BJ, Mooi WJ. Expression of the embryonal neural cell adhesion molecule N-CAM in lung carcinoma. Diagnostic usefulness of monoclonal antibody 735 for the distinction between small cell lung cancer and nonsmall cell lung cancer. J Pathol 159: 23-28, 1989.

8) Doyle LA, Borges M, Hussain A, Elias A, Tomiyasu T. An adherent subline of a unique small-cell lung cancer cell line downregulates antigens of the neural cell adhesion molecule. J Clin Invest 86: 1848-1854, 1990.

9) Figarella Branger DF, Durbec PL, Rougon GN. Differential spectrum of expression of neural cell adhesion molecule isoforms and L1 adhesion molecules on human neuroectodermal tumors. Cancer Res 50: 6364-6370, 1990.

10) Moolenaar CE, Muller EJ, Schol DJ, et al. Expression of neural cell adhesion molecule-related sialoglycoprotein in small cell lung cancer and neuroblastoma cell lines H69 and CHP-212. Cancer Res 50: 1102-1106, 1990.

11) Patel K, Bourne S, Coakham H, Kemshead JT. Expression of the neural cell adhesion molecule in human brain tumours. Biochem Soc Trans 18: 264,1990 .

12) Jin L, Hemperly JJ, Lloyd RV. Expression of neural cell adhesion molecule in normal and neoplastic human neuroendocrine tissues. Am J Pathol 138: 961-969, 1991.

13) Mechtersheimer G, Staudter M, Moller P. Expression of the natural killer cell-associated antigens CD56 and CD57 in human neural and striated 


\section{HASHIGUCHI et al}

muscle cells and in their tumors. Cancer Res 51: 1300-1307, 1991.

14) Van Camp B, Durie BG, Spier C, et al. Plasma cells in multiple myeloma express a natural killer cell-associated antigen: CD56 (NKH-1; Leu-19). Blood 76: 377-382, 1990.

15) Kern WF, Spier CM, Hanneman EH, Miller TP, Matzner M, Grogan TM. Neural cell adhesion molecule-positive peripheral T-cell lymphoma: A rare variant with a propensity for unusual sites of involvement. Blood 79: 2432-2437, 1992.

16) Shimoyama M. Diagnostic criteria and classification of clinical subtypes of adult T-cell leukaemia-lymphoma. A report from the Lymphoma Study Group (1984-87). Br J Haematol 79: 428-437, 1991.

17) Dickson $\mathrm{G}$, Gower HJ, Barton $\mathrm{CH}$, et al. Human muscle neural cell adhesion molecule (N-CAM): Identification of a muscle-specific sequence in the extracellular domain. Cell 50: 1119-1130, 1987.

18) Trinchieri G. Biology of natural killer cells. Adv Immunol 47: 187-376, 1989.

19) Hattori T, Uchiyama T, Toibana T, Takatsuki K, Uchino H. Surface phenotype of Japanese adult T-cell leukemia cells characterized by monoclonal antibodies. Blood 58: 645-647, 1981.
20) Doi S, Nasu K, Arita Y, et al. Immunohistochemical analysis of peripheral T-cell lymphoma in Japanese patients. Am J Clin Pathol 91: 152$158,1989$.

21) Kamihira $S$, Sohda $H$, Atogami $S$, et al. Phenotypic diversity and prognosis of adult T-cell leukemia. Leuk Res 16: 435-441, 1992.

22) Hayashi K, Nakamura $S$, Koshikawa $T$, et al. A case of neural cell adhesion molecule-positive peripheral T-cell lymphoma associated with human T-cell lymphotrophic virus type 1 showing an unusual involvement of the gastrointestinal tract during the course of the disease. Hum Pathol 25: 1251-1253, 1994.

23) Ohshima K, Haraoka S, Suzumiya J, et al. Absence of cytotoxic molecules in CD8-and/or CD56-positive adult T-cell leukaemia/lymphoma. Virchows Arch 435: 101-104, 1999.

24) Teshima $T$, Akashi $K$, Shibuya $T$, et al. Central nervous system involvement in adult T-cell leukemia/lymphoma. Cancer 65: 327-332, 1990.

25) Bashir R, Freedman A, Harris N, Bain K, Nadler L, Hochberg F. Immunophenotypic profile of CNS lymphoma: A review of eighteen cases. J Neurooncol 7: 249-254, 1989. 